\title{
ACUTE CHOLECYSTITIS - EARLY OR DELAYED SURGERY
}

\author{
Col KJ PHILIPOSE ${ }^{*}$, vsM, Wg Cdr VP BHALLA ${ }^{+}$ \\ Maj N KANNAN", Surg Lt Cdr S TANDON ${ }^{\star *}$
}

\begin{abstract}
A comparative study of early vs delayed cholecystectomy was conducted on 51 patients who presented with acute cholecystitis. Ultrasonography was accurate in diagnosing all cases of acute cholecystitis. Twenty four patients were managed by early surgery performed between 24 and 72 hours of onset of symptoms. Twenty seven were managed by delayed cholecystectomy between 8 weeks and 6 months of the acute episode. Early surgery required a longer operating time $(120+/-15$ minutes vs $90+/-15$ minutes $)$, more skill and had a marginally higher operative blood loss $(150 \mathrm{vs} 100 \mathrm{ml})$. Early surgery did not alter the decision or outcome of bile duct exploration. There were no fatalities or major complications. The total hospital stay was reduced in the early surgery group (10 vs 18 days). The study confirms the advantage of early cholecystectomy for treatment of acute cholecystitis.
\end{abstract}

MJAFI 1998; 54: 212-214

KEYWORDS : Acute cholecystitis; Early surgery.

\section{Introduction}

A cute cholecystitis is a severe complication of gall stone disease. The exact incidence of acute cholecystitis is unclear [1]. Reports of early cholecystectomy for acute cholecystitis started appearing in literature in 1950's. Ever since the timing of surgery has remained controversial. Most surgeons in India wait 6-8 weeks before performing cholecystectomy on a patient with acute cholecystitis [2]. Several studies have established the virtue of early cholecystectomy [3-5].

This prospective study was conducted between June 94 and June 96, at a tertiary referral hospital of the Armed Forces, to assess benefits and risks of early cholecystectomy in the setting.

\section{Material and Methods}

A prospective study of early versus delayed surgery in acute cholecystitis was performed from June 94 to June 96 . Fifty one patients admitted during the above period with clinical features of acute cholecystitis (AC) were studied.

Diagnosis of acute cholecystitis was established by the presence of established clinical criteria. Ultrasonographic (USG) correlation was used to confirm the diagnosis. Criteria to diagnose $\mathrm{AC}$ was dilated gall bladder, thickened walls, oedema of the gall bladder wall, stones within and at the neck of the gall bladder, fluid in the pericholecystic area and probe tenderness at the Murphy's point [6].

Twenty four patients with acute cholecystitis underwent early cholecystectomy (ES) between 24 and 48 hours of presentation. Twenty seven patients underwent delayed surgery (DS) between 8 weeks and 6 months after acute symptoms subsided. Criteria for selecting the modality of therapy was essentially based on the protocol of the admitting unit.

All patients were investigated to assess haematological parameters, liver function, liver enzyme elevation, coagulation profile, biochemical investigations to assess diabetes and renal disease. All patients in their acute phase were treated similarly with antibiotics (Inj Ampicillin $1 \mathrm{gm} 6 \mathrm{hrly}$, Inj Gentamicin $80 \mathrm{mg} 8 \mathrm{hrly}$ and Inj Metronidazole $500 \mathrm{mg} 8 \mathrm{hrly}$ ), intravenous fluids, nasogastric aspiration and monitored intensely for detecting the earliest change of deterioration.

At cholecystectomy, operative difficulty, operative time, blood loss, complications were noted. Per operative cholangiogram were done wherever indicated and necessary by a trans-cystic route. Total hospital stay was calculated for both groups.

\section{Results}

There were 59 patients who were treated for acute cholecystitis during the period June 94 to June 96 . Thirty five were treated conservatively during the acute episode and advised to follow up 6-8 weeks later for surgery, but only 27 reported back for DS. Twenty four patients underwent ES. There were 46 females and 5 males ranging in age between 19 and 74 years who underwent cholecystectomy. The mean age of patients in the DS group was 48 years and ES group was 49 years.

The patients reported on an average 2.5 days after onset of symptoms (range 1-10 days). Intercurrent diseases, hypertension were present in 14.8 per cent of DS and 29.16 per cent of ES patients. Clinical features were consistent with diagnosis in all patients. History of biliary dyspepsia was present in 42 of the patients. Three patients, 2 of the DS groups and 1 of ES group had jaundice. Ultrasonography could diagnose acute cholecystitis in all patients.

Patients placed on conservative line of treatment recovered from acute symptoms in 5-6 days, and needed on an average 9 days of hospitalization. Twenty seven patients of the DS group underwent surgery between 8 weeks and 6 months of the acute

\footnotetext{
Senior Advisor (Surgery), Base Hospital, Delhi Cantt 110010, + Reader, Department of Surgery, Armed Forces MEdical College, Pune 411 040, \# Graded Specialist (Surgery), 150 GH C/o 56 APO, ** Graded Specialist (Surgery), Command Hospital (SC) Pune.
} 
attack. Three patients presented with acute cholecystitis during the period of wait of surgery and underwent ES. All suffered from upper abdominal pain, dyspepsia, flatulence during this period which contributed to morbidity during the period of waiting.

Surgery in the DS group was performed by the Kochers incision or midline laparotomy. Operation time was $90+/-15$ minutes with a mean blood loss of $100 \mathrm{ml}$ (range $50-150 \mathrm{ml}$ ). Per operative cholangiography was done in 2 cases and the common bile duct was explored.The patients stayed in hospital two days pre op and 8-10 days post-operatively. The mean duration of hospitalization in this group of patients was 18 days (17-19 days) inclusive of earlier admission for acute attack.

The patients of the ES group were investigated and operated within 24 to 72 hours of onset of symptoms. The gall bladder was distended and inflamed in all cases with thin flimsy adhesion between the gall bladder and colon, omentum or intestines. Gangrene of the gallbladder was noted in 3 cases. In 5 cases the anatomy was distorted and marred by adhesions or inflamation and a fundus first method of cholecystectomy was performed. Pre-operative cholangiography was done in 2 and CBD exploration was done in one patient. Mean blood loss was $150 \mathrm{ml}$ (range 50-350 ml). The operation took $120+/-15$ minutes. Patients on an average stayed 12 days ( 10 to 14 days) in hospital.

There was no mortality or major complications. The post operative period of both groups did not reveal any gross differences with respect to duration of parenteral therapy, nasogastric suction, antibiotic therapy and complications of surgery other than superficial wound infection which was more in the ES group (8 vs 2). This did not affect the hospital stay of either group (Table 1).

TABLE $]$

\begin{tabular}{lcc}
\hline & DS & ES \\
\hline Patients & 27 & 24 \\
Mean age (years) & 48 & 49 \\
Associated disease & $14.8 \%$ & $29.16 \%$ \\
Jaundice & 2 & 1 \\
USG Dx & 27 & 24 \\
Opn time (mins) & $90 \pm 15$ & $120 \pm 15$ \\
Blood loss (ml) & $100 \pm 50$ & $150 \pm 50$ \\
Per op cholangio & 2 & 2 \\
CBD exploration & 2 & 1 \\
Wound infection & 2 & 8 \\
Hosp stay (days) & $18( \pm 1)$ & $12( \pm 2)$ \\
Bile culture +ve & 6 & 14 \\
\hline
\end{tabular}

\section{Discussion}

Acute cholecystitis is a common surgical emergency. To embark on a policy of early surgery for acute cholecystitis, the diagnosis needs to be accurate. Clinical examination is accurate in 80-85 per cent cases. Addition of ultrasonography increases accuracy of diagnosis to 92-96 per cent [7]. In our series USG was accurate in diagnosing all cases of acute cholecystitis.

Initial conservative management of acute cholecystitis followed by delayed surgery after 6-8 weeks is an established treatment policy. Approximately 22-27 per cent cases thus treated may be readmitted with acute symptoms in the convalescence period [4]. Three of our cases $(11.1 \%)$ were thus treated by ES during their second admission with AC. Most complications of acute cholecystitis, while on conservative therapy develop around the first week. The overall mortality of such complications is around 20 per cent which is more than four times the mortality of ES [8].

Most surgeons practicing ES in acute cholecystitis find dissection easier due to tissue planes being well separated by edema fluid. However one needs to be cautious in handling inflamed friable tissues, anatomical distortions and an oozy operating field [4,5]. Bile duct exploration and pre-operative cholangiography can be done wherever indicated without influencing the outcome of surgery.

Mortality and morbidity of early surgery and delayed surgery are comparable. Mortality figures rise sharply in the elderly, in whom the incidence of complications when managed conservatively is also high [4]. Most of our patients with acute cholecystitis, unlike the west, are not elderly. We had no mortality in patients managed by either method. Early post operative morbidity of early surgery was marginally higher compared to the DS group due to wound sepsis.

The total duration of hospitalization, in the ES group, was reduced to about half of what is necessary for completely treating acute cholecystitis. Early surgery reduces the duration which the patient has to wait for surgery while suffering from the disease. At a time when laparoscopic cholecystectomy is the order of the day ES has found favour even with the laparoscopic surgeons [9]. In the Indian setting where patients are poor rural folk depending on daily wages for subsistence, travelling great distance to a reasonable health care facility, reducing the patients financial burden is a great service. In the services where we want our soldier to return to productive duty at the earliest this modality of therapy would be of immense utility.

Early cholecystectomy for acute cholecystitis is an established procedure. It is still not so popular. In a country like ours where sophisticated investigations are often not available to all, the combination of meticulous clinical examination and USG of the abdomen should suffice to diagnose acute cholecystitis.

Early and interval cholecystectomy in the hands of a experienced surgeon have similar morbidity. The additional socioeconomic benefits to the individual patient and the organization should make early cholecystectomy the treatment of choice for acute cholecystitis 
in the Armed Forces.

\section{REFERENCES}

1. Zinner MJ, Schawartz SI, Ellis H, eds. Maingot's Abdominal Surgery 10th edn. Prentice Hall. 1996.

2. Kapoor VK, Sikora SS, Bal S. Current Practice in Biliary Surgery, 'The Current Scenario'. Ind J Gastroenterol 1994; 13: 49-51.

3. Van Der Linden W, Edlund G. Early vs Delayed cholecystectomy: Effect of change in management. $\mathrm{Br} \mathrm{J}$ Surg 1981; 68: 753-7.

4. Norby S, Herlin P, Holmin T, Sjodahl R, Tagesson C. Early or delayed cholecystectomy in acute cholecystitis? A clinical trial. Br J Surg 1983; 70: 163-5.
5. Dietrik NA, Cacioppo JC, Davis RP. The vanishing elective cholecystectomy. Arch Surg 1988; 123: 810-4.

6. Ralls PW, Colletti PM, Lapin SA et al. Real time sonography in suspected acute cholecystitis: prospective evaluation of primary and secondary signs. Radiology 1985; 155: 767.

7. Hi dalgo LA, Capella G, Pi-Figueras et al. The influence of age on the early surgical treatment of acute cholecystitis. Surg Gynaeco Obs 1989; 169: 393-6.

8. Nahrwold DL. Acute cholecystitis in Sabiston DC ed. Textbook of surgery. The biological basis of surgical practice, 14 edn WB Saunders, Philadelphia, $1991: 1050-7$.

9. Lo Chung-Mau, Liu Chi-Leung; Lai ECS, Fan Sheung-Tat, Wong S. Early vs Delayed laparoscopic cholecystectomy for treatment of acute cholecystitis. Ann Surg 1996; 223 : 37-42. 